American Journal of Infectious Diseases 5 (2): 118-125, 2009

ISSN 1553-6203

(C) 2009 Science Publications

\title{
Influence of Quercetin on Diabetes-Induced Alteration in CYP3A Activity and Bioavailability of Pioglitazone in Rats
}

\author{
${ }^{1}$ Sudhir Niranjan Umathe, ${ }^{1}$ Pankaj Vinod Dixit, \\ ${ }^{1}$ Jignesh Manubhai Vaghasiya and ${ }^{2}$ Nishant Sudhir Jain \\ ${ }^{1}$ University Department of Pharmaceutical Sciences, \\ Rashtrasant Tukadoji Maharaj Nagpur University, Nagpur-440033, India \\ ${ }^{2}$ J.L.C. College of Pharmacy, Wanadongri, Hingna Road, Nagpur-441110, India
}

\begin{abstract}
Problem statement: Quercetin-a common bioflavonoid, is present in herbal preparations consumed by diabetic patients along with routine anti-diabetic agents. We recently showed that quercetin increases the bioavailability of pioglitazone in non-diabetic rats. Thus, present study investigated whether this pharmacokinetic interaction is also evident in diabetic animals, especially because diabetic subjects have altered Gastrointestinal (GI) function and CYP3A activity. Approach: The study was carried out in alloxan-induced $\left(40 \mathrm{mg} \mathrm{kg}^{-1}\right.$, i.v.) diabetic rats. After 2 weeks of diabetes induction, rats were treated for 2 weeks with quercetin $\left(10 \mathrm{mg} \mathrm{kg}^{-1}\right.$, p.o.) or vehicle $(5 \%$ methyl cellulose, $10 \mathrm{~mL} \mathrm{~kg}^{-1}$ ). At the end of 4 weeks, these rats were used to investigate: (1) GI function in terms of gastric emptying and intestinal transit of semisolid barium sulphate meal; (2) CYP3A activity in liver and intestinal microsomes by erythromycin $\mathrm{N}$-demethylase assay; (3) plasma levels of orally and intravenously administered pioglitazone $\left(10 \mathrm{mg} \mathrm{kg}^{-1}\right.$, p.o.; $5 \mathrm{mg} \mathrm{kg}^{-1}$, i.v.). Results: The results revealed that diabetic rats exhibited: (1) delayed gastric emptying and intestinal transit; (2) decreased CYP3A activity and (3) a significant increase in the oral and intravenous $\mathrm{AUC}_{0-\infty}$ of pioglitazone as compared to non-diabetic rats. Quercetin treatment prevented the diabetes-induced GI dysfunction, whereas diabetes-induced decrease in CYP3A activity and increased bioavailability of pioglitazone remained unaffected. Conclusion: The results suggested that quercetin attenuated GI dysfunction but did not affect the bioavailability of pioglitazone in diabetic rats contrary to the increase reported in nondiabetic rats. However, the safety of co-joint use of quercetin containing herbs and pioglitazone in clinical practice requires further pharmacokinetic substantiation.
\end{abstract}

Key words: Herbal medicine, alloxan, diabetic gastroparesis, Erythromycin N demethylase

\section{INTRODUCTION}

Several herbal preparations are often used by the diabetic patients along with the routine antidiabetic agents with an intention to produce better glycemic control and to reduce diabetic complications ${ }^{[1,2]}$. Such herbal preparations often contain bioflavonoid that are antioxidant in nature and thus help to eliminate hyperglycemia-induced oxidative stress ${ }^{[1,3]}$. Some of the bioflavonoid are reported to inhibit the activity of CYP3A-a class of CYP450 isoenzymes ${ }^{[4-6]}$ and incidentally this class of enzymes is responsible for metabolizing pioglitazone and nateglinide, the often used oral antidiabetic agents ${ }^{[7,8]}$.

Recently, we have shown that quercetin-a bioflavonoid, decreases the metabolism of pioglitazone by inhibiting the CYP3A activity in non-diabetic rats and increases its bioavailability ${ }^{[9]}$. However, the CYP3A content and its activity in liver and intestinal tissues are low in diabetic condition ${ }^{[10]}$. Moreover, type 2 diabetes mellitus is associated with polymorphism of CYP3A $4^{[11]}$. In addition, diabetic subjects often exhibit variety of Gastrointestinal (GI) dysfunctions such as delayed gastric emptying and intestinal transit ${ }^{[12-14]}$. Under these circumstances, the drug-drug interaction between quercetin and pioglitazone evident in nondiabetic condition cannot be straightway extrapolated to diabetic condition.

Hence, the present study investigated: (1) the functional status of GIT; (2) the CYP3A activity in intestinal and liver tissues and (3) the pharmacokinetics of pioglitazone in alloxan-induced diabetic rats treated with vehicle or quercetin.

Corresponding Author: Sudhir N. Umathe, University Department of Pharmaceutical Sciences, Rashtrasant Tukadoji Maharaj Nagpur University, Mahatma Jyotiba Fuley Shaikshanik Parisar, Amravati Road, Nagpur (MS)-440033, India Tel: 91-712-2500324/91-712-2500355 Fax: 09373102858 
Am. J. Infect. Dis., 5 (2): 118-125, 2009

\section{MATERIALS AND METHODS}

Animals: Subjects were young, healthy adult male Sprague-Dawley rats (250-270 g), purchased from National Institute of Nutrition, Hyderabad (AP), India. Rats were housed in groups of 3-4 per cage in opaque polypropylene cages and maintained at $25 \pm 2^{\circ} \mathrm{C}$ with 12:12 h light/dark cycle (07:00-19.00 h) with rodent chow (Trimurti Feeds, Nagpur, MS, India) and water ad libitum. All the experimental procedures were approved by Institutional Animal Ethics Committee (Proposal no. 11 dated 27-07-2007) and according to the guidelines issued by Committee for the Purpose of Control and Supervision on Experiments on Animals, Ministry of Environment and Forests, Government of India, New Delhi, India.

Drugs: Alloxan monohydrate was purchased from Sigma-Aldrich (St. Louis, MO, USA). L-Histidine, NADPH, Tris $\mathrm{HCl}$ were purchased from SISCO Research Laboratories Pvt. Ltd. (Mumbai, India). Pioglitazone, rosiglitazone maleate and erythromycin were gifted by Wockhardt Research Center, Chikhalthana, Aurangabad, India. HPLC grade acetonitrile, methanol and all other chemicals of AR grade were purchased from RANKEM (Ranbaxy Fine Chemicals Ltd., New Delhi, India). Double distilled water was filtered through $0.45 \mu \mathrm{m}, 47 \mathrm{~mm}$ membrane filter (Ultipore ${ }^{\circledR} \mathrm{N}_{66}{ }^{\circledR}$ Nylon 6,6; PALL Life Science, Pall Pharmalab Filtration Pvt. Ltd., Mumbai, India) using Millipore $47 \mathrm{~mm}$ all glass filter apparatus and vacuum pump (Milford, MA, USA) and used throughout the experiments.

Experimental design and animal model: Rats were divided randomly into three body weight-matched groups $(\mathrm{n}=12)$. One group was non-diabetic control group and was administered saline $\left(1 \mathrm{~mL} \mathrm{~kg}^{-1}\right.$, i.v.); diabetes was induced in others by administering alloxan (40 $\mathrm{mg} \mathrm{kg}^{-1}$, i.v.) dissolved in cold saline $\left(1 \mathrm{~mL} \mathrm{~kg}^{-1}\right)$. Induction of diabetes was checked $48 \mathrm{~h}$ after injection of alloxan by glucometer. Two weeks after the induction of diabetes, diabetic rats were treated for further two weeks orally with vehicle $\left(5 \%\right.$ methylcellulose, $10 \mathrm{~mL} \mathrm{~kg}^{-1}$; diabetic control group) or with quercetin at a daily dose of $\left(10 \mathrm{mg} \mathrm{kg}^{-1}\right.$; quercetin treated group). At the end of 4 weeks, 3-4 animals each from a group were used for oral and intravenous pharmacokinetic studies and estimation of hepatic and intestinal CYP3A activity. The animals used for oral pharmacokinetic studies were later employed for GI function studies. The study design is represented schematically in Fig. 1.

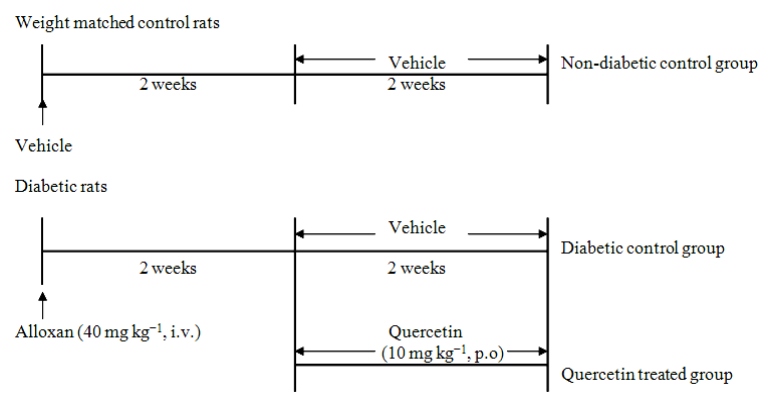

Fig. 1: Study design: At the end of 4 weeks 3-4 animals each from a group were used for oral and intravenous Pharmacokinetic (PK) studies and estimation of hepatic and intestinal CYP3A activity. The animals used for oral PK studies were employed for GI function studies.

The dose of alloxan was selected on the basis of previous report ${ }^{[15]}$. The dose of quercetin was selected from previous reports and our preliminary studies in such a way that treatment of diabetic rats for four weeks did not cause reversion of diabetes ${ }^{[16,17]}$. The duration of diabetes required for precipitation of gastroparesis was selected on the basis of previous report ${ }^{[18]}$ and our previous observations (unpublished data).

Estimation of blood glucose levels: Blood glucose levels were measured by GOD-POD method using commercially available glucometer (Ascensia Entrust, Bayer Healthcare LLC, USA) and expressed in mg $\mathrm{dL}^{-1}$. The rats showing fasting blood glucose levels more than $250 \mathrm{mg} \mathrm{dL}^{-1}$ after two days of alloxan administration were retained in the diabetic group.

Assessment of CYP3A activity in liver and intestinal microsomes: The influence of various treatments on the CYP3A activity in liver and intestinal microsomes was studied using the method of erythromycin $\mathrm{N}$ demethylase assay. In brief, at the end of four weeks, overnight fasted rats were euthanized by pentobarbitone overdose and the livers were perfused with $0.1 \mathrm{M}$ Phosphate Buffered Saline (PBS) and isolated. In addition, a piece of intestine $\sim 25 \mathrm{~cm}$ ) was isolated and cleaned with PBS. The intestinal and liver microsomes were prepared by methods reported by us earlier ${ }^{[9]}$.

The mixture of microsomal suspension $(0.1 \mathrm{~mL}$, $25 \%)$, erythromycin $(0.1 \mathrm{~mL}, 10 \mathrm{mM})$ and potassium phosphate $(0.6 \mathrm{ml}, 100 \mathrm{mM}, \mathrm{pH} 7.4)$ was incubated at $37^{\circ} \mathrm{C}$. The reaction was initiated by adding NADPH $(0.1 \mathrm{~mL}, 10 \mathrm{mM})$ and terminated after $10 \mathrm{~min}$, by adding ice-cold trichloroacetic acid solution $(0.5 \mathrm{~mL}$, $12.5 \% \mathrm{w} / \mathrm{v})$. The mixture was centrifuged $(2000 \times \mathrm{g})$ to 
remove proteins. $1.0 \mathrm{~mL}$ of $\mathrm{NASH}$ reagent $(2 \mathrm{M}$ ammonium acetate, $0.05 \mathrm{M}$ glacial acetic acid, $0.02 \mathrm{M}$ acetylacetone) was mixed with $1.0 \mathrm{ml}$ of supernatant and heated in a water bath at $50^{\circ} \mathrm{C}$ for $30 \mathrm{~min}$. After cooling the absorbance was measured at $412 \mathrm{~nm}$. The activity was calculated from standards (1-100 $\mu \mathrm{M}$ formaldehyde) prepared by substituting sample with standard solution, which were run in parallel. All the samples were run in duplicate. The CYP3A activity was expressed as $\mathrm{nM}$ of formaldehyde obtained per milligram of protein per min.

Assessment of gastric emptying and intestinal transit: Gastric emptying of a non-nutrient semi-solid meal was assessed by previously reported method ${ }^{[19]}$. In brief, at the end of four weeks and overnight fasting, a suspension of $7.5 \mathrm{~g}$ barium sulphate in $10 \mathrm{ml}$ water was given orally to rats in a volume of $2 \mathrm{~mL} / 100 \mathrm{~g}$ body weight. After $30 \mathrm{~min}$, rats were euthanized by pentobarbitone overdose. The abdomen was cut open and esophageal and pyloric ends of stomach were clamped with a string to prevent any leakage of its residual content. The stomach was weighed along with its contents and then incised, the contents removed and stomach weighed again. The gastric barium sulphate content was calculated from the weight difference between the filled and empty stomach and the amount of $\mathrm{BaSO}_{4}$ suspension administered was determined by weighing the dose (syringe) before administration. The percent gastric emptying rate was calculated by the following formula:

$$
\% \mathrm{GE}=\frac{\mathrm{W} 1-\mathrm{W} 2}{\mathrm{~W} 1} \times 100
$$

Where:

$$
\begin{aligned}
\% \mathrm{GE}= & \text { Percent Gastric Emptying } \\
\mathrm{W} 1= & \mathrm{Wt} \text { of } \mathrm{BaSO}_{4} \text { suspension administered } \\
\mathrm{W} 2= & \mathrm{Wt} \text { of stomach before washing-Wt of stomach } \\
& \text { after washing }
\end{aligned}
$$

Intestinal transit was determined as the percentage of movement of barium sulphate in the intestine in relation to the whole length of the gut as determined by visual inspection of the test meal passage in the intestine.

Pharmacokinetic and bioavailability studies in rats: At the end of four weeks, rats were fasted overnight and were fed $4 \mathrm{~h}$ after dosing pioglitazone orally. For intravenous studies animals were not fasted. The animals had free access to water during all these studies. Each rat was given either a single intravenous dose $\left(5 \mathrm{mg} \mathrm{kg}^{-1}\right)$ or oral dose $\left(10 \mathrm{mg} \mathrm{kg}^{-1}\right)$ of pioglitazone ( $\mathrm{n}=3-4$ each). The intravenous doses were administered as a bolus via the saphenous vein and the oral doses by oral gavage. Pioglitazone was administered as a solution in a vehicle composed of $0.1 \mathrm{M}$ citric acid in dose volume of $10 \mathrm{~mL} \mathrm{~kg}^{-1}$ for oral administration and in (30\% propylene glycol+3\% DMSO) mixture at a dose volume of $2 \mathrm{~mL} \mathrm{~kg}^{-1}$ for intravenous studies. Blood samples $(0.3 \mathrm{~mL})$ were withdrawn through tail vein from unrestrained animals ${ }^{[20]}$ and collected in heparinized tubes at $0.5,1,2,4,8$ and $24 \mathrm{~h}$ after oral administration and $0.083,0.5,1,2,8,12$ and $18 \mathrm{~h}$ after intravenous administration of pioglitazone. Plasma was prepared immediately by centrifugation and stored at $-20^{\circ} \mathrm{C}$ until samples were analyzed.

Pioglitazone concentration was determined as reported by us earlier ${ }^{[9]}$. In brief, to $100.0 \mu \mathrm{L}$ of plasma sample, $50.0 \mu \mathrm{L}$ of rosiglitazone (12.5 mg in methanol) solution as internal standard and $100.0 \mu \mathrm{L}$ of acetonitrile were added to precipitate the proteins. The mixture was vortex mixed for 5 min after which it was centrifuged at $10,000 \times \mathrm{g}$ for $10 \mathrm{~min}$ and $20.0 \mu \mathrm{L}$ of the supernatant was injected onto the HPLC system for analysis. The UV detector was set at $269 \mathrm{~nm}$. C18 (2) column $\left(4.6 \times 250 \mathrm{~mm}, 100^{\circ} \mathrm{A}\right)$ Luna, PHENOMENEX, USA was set at $30^{\circ} \mathrm{C}$. The flow rate was $1.2 \mathrm{~mL} \mathrm{~min}^{-1}$ and the mobile phase consisted of $25.0 \mathrm{mM}$ phosphate buffer ( $\mathrm{pH} 3.0)$, acetonitrile and methanol in a ratio of 70:25:5 (v/v/v). The method was linear over 0.3-20 $\mu \mathrm{g} \mathrm{mL}^{-1}$ plasma pioglitazone concentration.

Pharmacokinetic analysis: Plasma concentration-time curve for pioglitazone was plotted and the pharmacokinetic parameters were calculated using noncompartmental pharmacokinetic model of WINNONLIN $^{\circledR}$ (Version 1.5, SCI software, Statistical Consulting, Inc., Apex, NC, USA).

Statistical analysis: Wherever required the data is analyzed by using one-way ANOVA followed by Newman-Keuls test for multiple comparisons. $\mathrm{p}<0.05$ was considered statistically significant.

\section{RESULTS}

Induction of diabetes: Single intravenous dose of alloxan (40 mg kg${ }^{-1}$ ) was sufficient to induce diabetes in the rats and the blood glucose levels were above the threshold $\left(250 \mathrm{mg} \mathrm{dL}^{-1}\right)$ in all the animals during four weeks. The mortality due to diabetes was about $20 \%$. The blood glucose levels were checked weekly to ensure maintenance of diabetic state. The initial and final blood glucose values along with body weights, water intake and urine output are shown in Table 1. 
Am. J. Infect. Dis., 5 (2): 118-125, 2009

Table 1: General features of experimental rats

\begin{tabular}{|c|c|c|c|c|c|}
\hline \multirow[b]{2}{*}{ Sr. No. } & \multirow[b]{2}{*}{ Parameter } & \multicolumn{3}{|l|}{ Groups } & \multirow[b]{2}{*}{ One-way ANOVA statistics } \\
\hline & & Vehicle control & Diabetes & Diabetes + Quercetin & \\
\hline 1 & Initial blood glucose $\left(\mathrm{mg} \mathrm{dL}^{-1}\right)$ & $90.80 \pm 11.1$ & $401.30 \pm 84.1 * * *$ & $429.4 \pm 73.8$ & $\mathrm{~F}(2,33)=100.4, \mathrm{p}<0.0001$ \\
\hline 2 & Final blood glucose $\left(\mathrm{mg} \mathrm{dL}^{-1}\right)$ & $85.30 \pm 10.3$ & $386.50 \pm 43.2 * * *$ & $382.6 \pm 56.6$ & $F(2,24)=170.6, p<0.0001$ \\
\hline 3 & Terminal body weight (g) & $260.50 \pm 8.9$ & $191.30 \pm 15.9 * * *$ & $203.3 \pm 16.3$ & $F(2,28)=78.18, p<0.0001$ \\
\hline 4 & Food intake $\left(\mathrm{g} \mathrm{rat}^{-1}\right.$ day $\left.^{-1}\right)$ & $7.16 \pm 1.33$ & $9.44 \pm 0.88 * * *$ & $9.8 \pm 1.47$ & $\mathrm{~F}(2,28)=13.94, \mathrm{p}<0.0001$ \\
\hline 5 & Water intake $\left(\mathrm{mL}^{-1}\right.$ rat $^{-1}$ day $\left.^{-1}\right)$ & $29.50 \pm 5.3$ & $50.50 \pm 6.2 * * *$ & $47.6 \pm 7.10$ & $\mathrm{~F}(2,28)=36.40, \mathrm{p}<0.0001$ \\
\hline
\end{tabular}

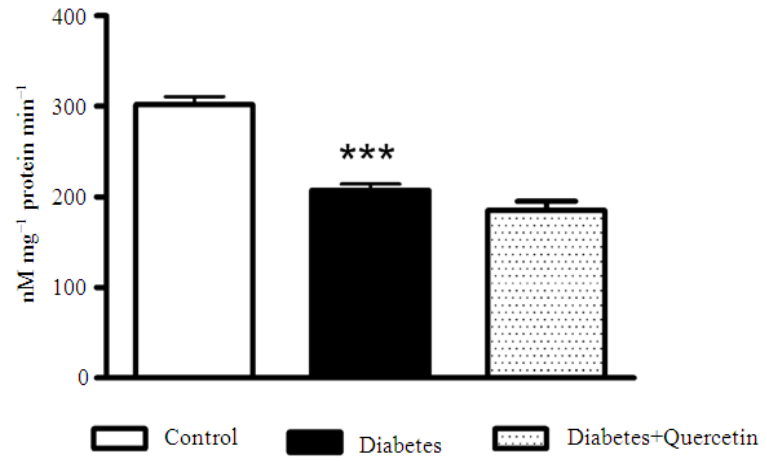

Fig. 2: Effect of quercetin on diabetes-induced changes in intestinal microsomal CYP3A activity. At the end of four weeks, overnight fasted rats were euthanized by pentobarbitone overdose; a piece of intestine $(\sim 25 \mathrm{~cm})$ was isolated and washed with PBS and microsomes were prepared, which were used to determine the CYP3A activity by Erythromycin Ndemethylase assay run in duplicate. Each bar represents mean \pm SEM of 6-8 observations. ***: $p<0.001 \mathrm{Vs}$ non-diabetic control group (Neuman-Keuls post hoc test)

CYP3A activity studies: Figure 2 and 3 exhibits the extent of erythromycin N-demethylation due to CYP3A activity in intestinal and liver microsomes. One-way ANOVA revealed that all the treatments had a significant influence on the CYP3A activity in both intestine $[\mathrm{F}(2,19)=52.74, \mathrm{p}<0.0001]$ and liver microsomes $[\mathrm{F}(2,21)=155.6, \mathrm{p}<0.0001]$. The post hoc analysis further reveals that the CYP3A activity in intestinal and liver microsomes of diabetic animals was significantly reduced $(\mathrm{p}<0.001)$ as compared to nondiabetic control animals. Further, two weeks of quercetin $\left(10 \mathrm{mg} \mathrm{kg}{ }^{-1}\right)$ treatment had no influence $(\mathrm{p}>0.05)$ on diabetes-induced changes in CYP3A activity.

Gastrointestinal functional studies: Figure 4 and 5 shows the diabetes-induced changes on gastric emptying and intestinal transit along with the influence of quercetin treatment on the same. One-way ANOVA

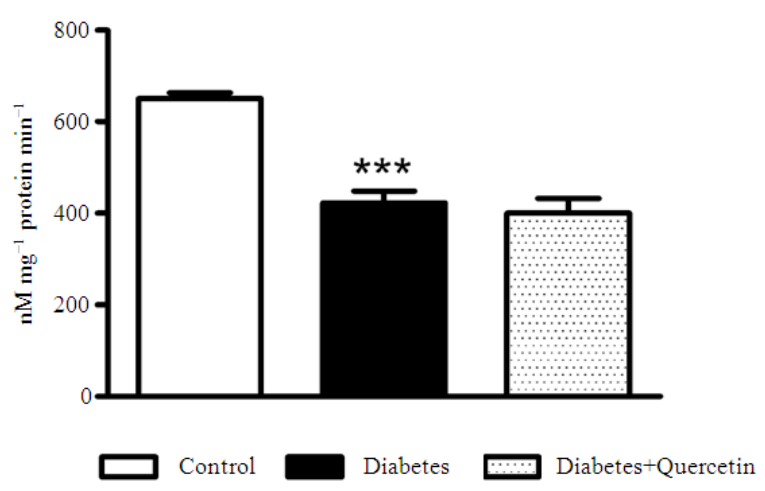

Fig. 3: Effect of quercetin on diabetes-induced changes in liver microsomal CYP3A activity. At the end of four weeks, overnight fasted rats were euthanized by pentobarbitone overdose and the livers were perfused with $0.1 \mathrm{M}$ Phosphate Buffered Saline (PBS); isolated and the microsomes prepared, which were used to determine the CYP3A activity by Erythromycin $\mathrm{N}$-demethylase assay run in duplicate. Each bar represents mean \pm SEM of 6-8 observations. $* * *$ : $p<0.001 \mathrm{Vs}$ non-diabetic control group (Neuman-Keuls post hoc test)

reveals a significant influence of all treatments on gastric emptying $[\mathrm{F}(2,9)=16.94, \mathrm{p}=0.0009]$ and intestinal transit $[\mathrm{F}(2,9)=5.635, \mathrm{p}=0.0259]$. Four weeks of diabetes significantly reduced the gastric emptying $(\mathrm{p}<0.01)$ and intestinal transit $(\mathrm{p}<0.05)$. Quercetin administered two weeks after the induction of diabetes, restored the diabetes-induced changes in gastric emptying $(\mathrm{p}<0.01)$ and intestinal transit $(\mathrm{p}<0.05)$ to normal levels.

Pharmacokinetic studies: The mean plasma concentration-time profiles of pioglitazone after its oral and intravenous administration at a dose of 10 and $5 \mathrm{mg}$ $\mathrm{kg}^{-1}$ respectively, to non-diabetic rats, vehicle treated diabetic rats and quercetin treated diabetic rats are shown in Fig. 6 and 7 and some relevant pharmacokinetic parameters are shown in Table 2 and 3. 
Am. J. Infect. Dis., 5 (2): 118-125, 2009

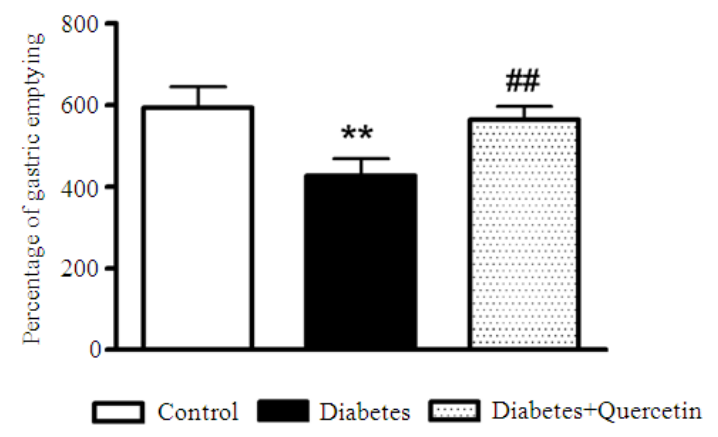

Fig. 4: Effect of quercetin on diabetes-induced changes in gastric emptying. At the end of protocol, overnight fasted rats were given a test meal consisting of a suspension of $7.5 \mathrm{~g}$ barium sulphate in $10 \mathrm{~mL}$ water $(2 \mathrm{~mL} / 100 \mathrm{~g}$ body weight/p.o.). After $30 \mathrm{~min}$, rats were euthanized by pentobarbitone overdose and the gastric emptying was calculated by formula given in the text. Each value represents mean $\pm \mathrm{SD}$ of 3-4 observations. **: $\mathrm{p}<0.01 \mathrm{Vs}$ non-diabetic control group, \#: p<0.01 Vs diabetic control group respective control group (Neuman-Keuls post hoc test)

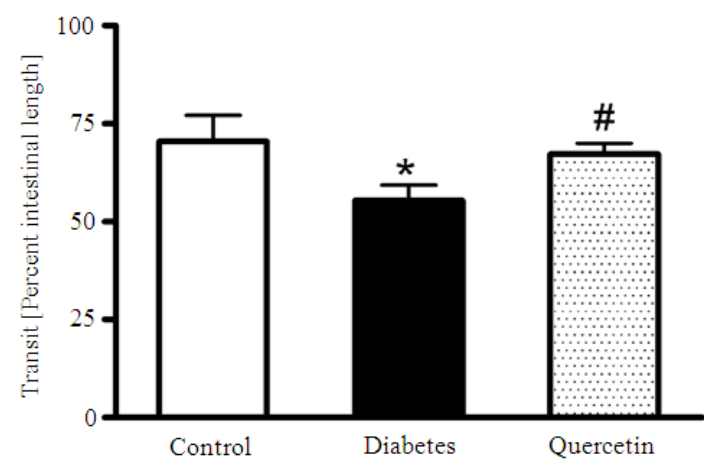

Fig. 5: Effect of quercetin on diabetes-induced changes in intestinal transit. At the end of protocol, overnight fasted rats were given a test meal consisting of a suspension of $7.5 \mathrm{~g}$ barium sulphate in $10 \mathrm{~mL}$ water $(2 \mathrm{~mL} / 100 \mathrm{~g}$ body weight/p.o.). After $30 \mathrm{~min}$, rats were euthanized by pentobarbitone overdose and the intestinal transit was determined as percentage of movement of barium sulphate in the intestine in relation to the whole gut length as determined by visual inspection of the test meal passage in the intestine. Each value represents mean \pm SD of 3-4 observations. *: $\mathrm{p}<0.05$ Vs non-diabetic control group, ${ }^{\#}: \mathrm{p}<0.05$ Vs diabetic control group respective control group (Neuman-Keuls post hoc test)

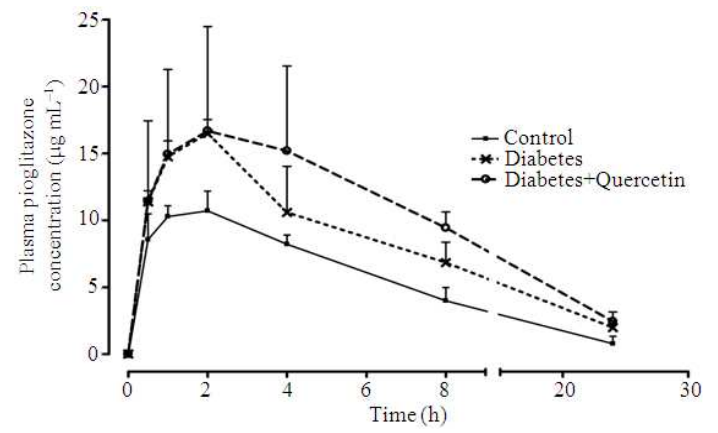

Fig. 6: The mean plasma concentration-time profiles of pioglitazone after its oral administration to nondiabetic, diabetic and quercetin treated group. At the end of the experiment, overnight fasted rats were given oral gavage of pioglitazone (10 mg kg${ }^{-1}$ in $0.1 \mathrm{M}$ citric acid solution). Blood samples $(0.3 \mathrm{~mL})$ were withdrawn through tail vein from unrestrained animals and collected in heparinized tubes at $0.5,1,2,4,8$ and $24 \mathrm{~h}$ time interval and stored at $-20^{\circ} \mathrm{C}$ till HPLC analysis. Each value represents mean \pm SD of 3-4 observations

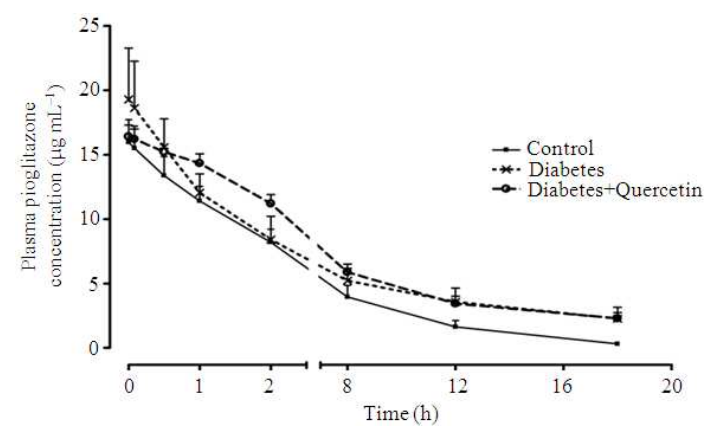

Fig. 7: Mean plasma concentration-time profiles of pioglitazone after its intravenous administration to non-diabetic, diabetic and quercetin treated group. At the end of the experiment, rats were given an intravenous bolus of pioglitazone $5 \mathrm{mg} \mathrm{kg}{ }^{-1}$ in $(30 \%$ propylene glycol $+3 \%$ DMSO mixture]. Blood samples $(0.3 \mathrm{~mL})$ were withdrawn through tail vein from unrestrained animals and collected in heparinized tubes at $0.083,0.5,1,2,8,12$ and $18 \mathrm{~h}$ time interval and stored at $-20^{\circ} \mathrm{C}$ till HPLC analysis. Each value represents mean $\pm \mathrm{SD}$ of 3 observations

One-way ANOVA revealed a significant influence of all the treatments on the oral and intravenous pharmacokinetics of pioglitazone. The $\mathrm{AUC}_{0-\infty}(81 \%$ increase), $\mathrm{T}_{1 / 2}, \mathrm{Vd}$ and MRT of pioglitazone was significantly increased $(\mathrm{p}<0.05)$ and $\mathrm{K}_{\mathrm{el}}$ and $\mathrm{Cl}$ was significantly decreased $(\mathrm{p}<0.05)$ in diabetic rats after its 
Am. J. Infect. Dis., 5 (2): 118-125, 2009

Table 2: Pharmacokinetic parameters of pioglitazone in various treatment groups after its oral administration

\begin{tabular}{|c|c|c|c|c|c|}
\hline \multirow[b]{2}{*}{ Sr. No. } & \multirow{2}{*}{$\begin{array}{l}\text { Pharmacokinetic } \\
\text { parameters }\end{array}$} & \multicolumn{3}{|c|}{ Pioglitazone (10 $\mathrm{mg} \mathrm{kg}^{-1}$, p.o.) } & \multirow[b]{2}{*}{ One-way ANOVA statistics } \\
\hline & & Vehicle control & Diabetes & Diabetes + Quercetin & \\
\hline 1 & $\mathrm{~T}_{\max }(\mathrm{h})$ & $1.7 \pm 0.5$ & $2.0 \pm 0.0$ & $4.0 \pm 3.4$ & $\mathrm{~F}(2,7)=1.379, \mathrm{p}=0.3127$ \\
\hline 2 & $\mathrm{C}_{\max }\left(\mu \mathrm{g} \mathrm{mL}^{-1}\right)$ & $10.9 \pm 1.2$ & $16.4 \pm 1.1$ & $17.0 \pm 7.3$ & $\mathrm{~F}(2,7)=2.515, \mathrm{p}=0.1503$ \\
\hline 3 & $\operatorname{AUC}_{0-\infty}\left(\mu \mathrm{g} \mathrm{h} \mathrm{mL}^{-1}\right)$ & $99.7 \pm 16.6$ & $173.0 \pm 30.7^{*}$ & $214.8 \pm 57.8$ & $\mathrm{~F}(2,7)=9.212, \mathrm{p}=0.0110$ \\
\hline
\end{tabular}

After 4 weeks of various treatments rats were overnight fasted and were administered with pioglitazone $\left(10 \mathrm{mg} \mathrm{kg}^{-1}\right.$, p.o.). Blood (0.3 mL) was collected in heparinized tubes at $0.5,1,2,4,8$ and $24 \mathrm{~h}$ after oral administration and the plasma concentrations were determined by HPLC. Tmax: Time to reach Cmax; Cmax: Peak plasma concentration; AUC: Area under the plasma concentration curve. All values are mean \pm SD $(n=3-4) *: p<0.05$ Vs vehicle treated control group (One-way ANOVA followed by Newman-Keuls test)

Table 3: Pharmacokinetic parameters of pioglitazone in various treatment groups after its intravenous administration

\begin{tabular}{|c|c|c|c|c|c|}
\hline \multirow[b]{2}{*}{ Sr. No. } & \multirow{2}{*}{$\begin{array}{l}\text { Pharmacokinetic } \\
\text { Parameters }\end{array}$} & \multicolumn{3}{|c|}{ Pioglitazone $\left(5 \mathrm{mg} \mathrm{kg}^{-1}\right.$, i.v. $)$} & \multirow[b]{2}{*}{ One-way ANOVA statistics } \\
\hline & & Vehicle control & Diabetes & Diabetes + Quercetin & \\
\hline 1 & $\mathrm{C}_{\max }\left(\mu \mathrm{g} \mathrm{mL}^{-1}\right)$ & $15.900 \pm 1.700$ & $29.300 \pm 14.3$ & $16.400 \pm 0.9$ & $F(2,6)=2.477, p=0.1644$ \\
\hline 2 & $\operatorname{AUC}_{0-\infty}\left(\mu \mathrm{g} \mathrm{h} \mathrm{mL}^{-1}\right)$ & $74.400 \pm 9.800$ & $127.800 \pm 30.5^{*}$ & $137.900 \pm 16.2$ & $F(2,6)=8.103, p=0.0197$ \\
\hline 3 & $\mathrm{~K}_{\mathrm{el}}(1 / \mathrm{h})$ & $0.250 \pm 0.010$ & $0.090 \pm 0.03 * * *$ & $0.090 \pm 0.02$ & $F(2,6)=62.67, p<0.0001$ \\
\hline 4 & $\mathrm{~T}_{1 / 2}(\mathrm{~h})$ & $2.690 \pm 0.100$ & $7.950 \pm 2.3^{*}$ & $7.560 \pm 1.2$ & $F(2,6)=10.79, p=0.0103$ \\
\hline 5 & $\mathrm{Vz} / \mathrm{F}(1)$ & $0.260 \pm 0.030$ & $0.440 \pm 0.05 * *$ & $0.390 \pm 0.04$ & $F(2,6)=17.03, p=0.0034$ \\
\hline 6 & $\mathrm{Cl} / \mathrm{F}(1 / \mathrm{h})$ & $0.067 \pm 0.009$ & $0.041 \pm 0.011 * *$ & $0.036 \pm 0.003$ & $F(2,6)=11.96, p=0.0081$ \\
\hline 7 & $\operatorname{MRT}(\mathrm{h})$ & $5.060 \pm 0.410$ & $11.050 \pm 3.31^{*}$ & $10.120 \pm 1.45$ & $F(2,6)=7.059, p=0.0265$ \\
\hline
\end{tabular}

After 4 weeks of various treatments rats were administered with pioglitazone $\left(5 \mathrm{mg} \mathrm{kg}^{-1}\right.$, i.v.). Blood $(0.3 \mathrm{ml})$ was collected in heparinized tubes at $0.083,0.5,1,2,8,12$ and $18 \mathrm{~h}$ after intravenous administration and the plasma concentrations were determined by HPLC. Cmax: Peak plasma concentration; AUC: Area under the plasma concentration curve; $\mathrm{K}_{\mathrm{el}}$ : Elimination rate constant; $\mathrm{T}_{1 / 2}$ : Half-life; Vz/F: Volume of distribution; $\mathrm{Cl} / \mathrm{F}$ : Clearance; MRT: Mean residence time. All values are mean $\pm \mathrm{SD}(\mathrm{n}=3) ; *$ : $\mathrm{p}<0.05$; **: $\mathrm{p}<0.01$; ***: $\mathrm{p}<0.001$ Vs vehicle treated control group (One-way ANOVA followed by Newman-Keuls test)

intravenous administration. Similarly, the $\mathrm{AUC}_{0-\infty}$ of pioglitazone was significantly increased $(\mathrm{p}<0.05$; $73.0 \%$ increase) in diabetic rats after its oral administration. However, other pharmacokinetic parameters were not significantly affected.

Quercetin treatment had no influence $(\mathrm{p}>0.05)$ on the diabetes-induced changes in the oral and intravenous pharmacokinetics of pioglitazone.

\section{DISCUSSION}

Pioglitazone is known to sensitize the tissues to insulin to produce its antidiabetic action ${ }^{[21]}$. If given along with a sulphonylurea or insulin, it often leads to severe hypoglycemia ${ }^{[22,23]}$. In view of this risk factor, its bioavailability is therapeutically crucial in view of possible pharmacokinetic drug-drug interactions. We had earlier shown that administration of pioglitazone along with quercetin to non-diabetic rats increases its bioavailability, as it is principally metabolized by CYP3A and quercetin inhibits the same. However, it is difficult to extrapolate such possibility in diabetic condition, particularly because diabetic rats have altered GI function and CYP3A activity. Therefore, the present investigation was carried out to study the fate of pharmacokinetic drug-drug interaction between quercetin and pioglitazone in diabetic condition.

These studies revealed that the Cmax and Area Under The Curve (AUC) of orally given pioglitazone were higher in alloxan-induced diabetic rats as compared to non-diabetic rats and the results in nondiabetic rats were in accordance with the previous reports ${ }^{[24]}$. However when given intravenously, AUC was higher, clearance was lower and Cmax remained unaffected in diabetic rats as compared with nondiabetic group. These observations indicate that the bioavailability of pioglitazone is as such higher in diabetic group as compared to non-diabetic group. The studies further revealed that pretreatment with quercetin did not influence the increased bioavailability of pioglitazone in diabetic rats and this is contrary to our previous observation that quercetin increases the same in non-diabetic rats ${ }^{[9]}$.

The GI function studies revealed that the diabetic group exhibited significant delay in gastric emptying and intestinal transit and thus mimicked the condition of diabetic gastroparesis seen in humans after long standing diabetes mellitus. In addition, it was observed that treatment with quercetin significantly prevented these diabetes-induced changes in GI function. Recently, we have reported that reduced NO levels in GI tissues is the pivotal reason for diabetes-induced GI dysfunction $^{[19]}$. Quercetin is reported to enhance the bioavailability of $\mathrm{NO}$ in diabetic rat aortas ${ }^{[25]}$. Thus, quercetin might have produced beneficial effects in diabetic rats through modulation of NO levels in the GIT. 
The delay of gastric emptying and intestinal transit is normally expected to postpone the Tmax, while improvement by quercetin is expected normalize it. However, the Tmax in diabetic group was same as that of non-diabetic group, indicating that prevailing GI function had no contribution to the bioavailability of pioglitazone and hence quercetin-induced improved GI function did not show any change in the Tmax. It is known that diabetic gastroparesis affects the emptying of solid meal while the emptying of liquid meal remains unaltered ${ }^{[26,27]}$. Incidentally, in the present investigation pioglitazone was administered in the solution form.

The diabetes-or quercetin-induced changes in CYP3A activity could be responsible for the changes in Cmax and reduction in clearance of pioglitazone. The erythromycin N-demethylase assay revealed decreased CYP3A activity in liver and intestinal microsomes obtained from diabetic group. These observations are in accordance to the earlier reported changes in the CYP3A activity in diabetic condition ${ }^{[10]}$. The CYP3A activity in these tissues was uninfluenced by quercetin treatment to diabetic group. In our earlier study we found that quercetin significantly inhibited CYP3A activity in non-diabetic rats, which is not evident in diabetic rats in the present investigation. Western blotting studies have reported that the content of CYP3A of liver and intestine is as such low in diabetic condition $^{[10]}$. Thus, inadequate availability of CYP3A and decreased metabolism could be the possible reason for higher Cmax and AUC of pioglitazone in diabetic condition. For the same reason, quercetin-induced inhibition of CYP3A was not evident in diabetic group, which is otherwise seen in non-diabetic group in our earlier studies.

Thus, these studies reveal that the bioavailability of pioglitazone is higher in diabetic condition but remains unaffected by quercetin treatment. Part of this observation is contrary to a clinical report wherein type II diabetic patients exhibited normal clearance of pioglitazone ${ }^{[7]}$. However, the study did not assess CYP3A activity and/or the functional status of GIT in these patients.

\section{CONCLUSION}

The present investigations revealed that quercetin treatment improved diabetes-induced GI dysfunction with no concurrent influence on the hepatic and intestinal CYP3A activity and hence the bioavailability of pioglitazone. However, extensive clinical pharmacokinetic studies are necessary to extrapolate these observations for therapeutic enrichment.

\section{ACKNOWLEDGEMENT}

The study was supported by University Grants Commission, India, under Major Research Project Grant [F31-79/2005(SR)].

\section{REFERENCES}

1. Jung, M., M. Park, H.C. Lee, Y.H. Kang, E.S. Kang and S.K. Kim, 2006. Antidiabetic agents from medicinal plants. Curr. Med. Chem., 13: 1203-1218. http://www.bentham.org/cmc/contabs/cmc13-10.htm\#8

2. Wheaton, A.G., H.M. Blanck, Z. Gizlice and M. Reyes, 2005. Medicinal herb use in a population-based survey of adults: Prevalence and frequency of use, reasons for use and use among their children. Ann. Epidemiol., 15 : 678-685. DOI: 10.1016/J.ANNEPIDEM.2004.09.002

3. Bonnefont-Rousselot, D., 2004. The role of antioxidant micronutrients in the prevention of diabetic complications. Treat. Endocrinol., 3: 41-52. http://www.ingentaconnect.com/content/adis/end/2 004/00000003/00000001/art00005

4. Fujita, K., M. Hidaka, N. Takamura, K. Yamasaki, T. Iwakiri, M. Okumura, H. Kodama, M. Yamaquchi, T. Ikenoue and K. Arimori, K., 2003. Inhibitory effects of citrus fruits on cytochrome P450 3A (CYP3A) activity in humans. Biol. Pharm. Bull., 26: 1371-1373. DOI: $10.1248 / \mathrm{bpb} .26 .1371$

5. Izzo, A.A., 2005. Herb-drug interactions: An overview of the clinical evidence. Fundam. Clin. Pharmacol., 19: 1-16. http://www.ncbi.nlm.nih.gov/pubmed/15660956

6. Pal, D. and A.K. Mitra, 2006. MDR- and CYP3A4mediated drug-herbal interactions. Life Sci., 78: 2131-2145. DOI: 10.1016/J.LFS.2005.12.010

7. Eckland, D.A. and M. Danhof, 2000. Clinical pharmacokinetics of pioglitazone. Exp. Clin. Endocrinol. $\quad$ Diab., 108: S234-242. http://direct.bl.uk/bld/PlaceOrder.do?UIN=087321 393\&ETOC $=$ RN\& from=searchengine

8. Weaver, M.L., B.A. Orwig, Rodriguez, E.D. Graham, J.A. Chin, M.J. Shapiro, J.F. McLeod and J.B. Mangold, 2001. Pharmacokinetics and metabolism of nateglinide in humans. Drug Metab. Dispos., 29: 415-421.

http://dmd.aspetjournals.org/cgi/content/full/29/4/415

9. Umathe, S.N., P.V. Dixit, V. Kumar, K.U. Bansod and M.M. Wanjari, 2008. Quercetin pretreatment increases the bioavailability of pioglitazone in rats: Involvement of CYP3A inhibition. Biochem. Pharmacol., $\quad 75: \quad$ 1670-1676. $\quad$ DOI: 10.1016/j.bcp.2008.01.010 
10. Borbas, T., B. Benko, B. Dalmadi, I. Szabo and K. Tihanyi, 2006. Insulin in flavin-containing monooxygenase regulation. Flavin-containing monooxygenase and cytochrome $\mathrm{P} 450$ activities in experimental diabetes. Eur. J. Pharm. Sci., 28: 51-58. DOI: 10.1016/J.EJPS.2005.12.011

11. Yamada, Y., H. Matsuo, S. Watanabe, K. Kato, K. Yajima, T. Hibino, K. Yokoi, S. Ichihara, N. Metoki, H. Yoshida, K. Satoh and Y. Nozawa, 2007. Association of a polymorphism of CYP3A4 with type 2 diabetes mellitus. Int. J. Mol. Med., 20: 703-707. http://www.ncbi.nlm.nih.gov/pubmed/17912464

12. Horowitz, M., M. Edelbroek, R. Fraser, A. Maddox and J. Wishart, 1991. Disordered gastric motor function in diabetes mellitus. Recent insights into prevalence, pathophysiology, clinical relevance and treatment. Scand. J. Gastroenterol., 26: 673-684. DOI: $10.3109 / 00365529108998583$

13. Hermann, R., H.J. Wildgrube, P. Ruus, G. Niebch, H. Nowak and C.H. Gleiter, 1998. Gastric emptying in patients with insulin dependent diabetes mellitus and bioavailability of thioctic acid-enantiomers. Eur. J. Pharm. Sci., 6: 27-37. DOI: 10.1016/S0928-0987(97)00065-1

14. Fraser, R.J., M. Horowitz, A.F. Maddox, P.E. Harding, B.E. Chatterton and J. Dent, 1990. Hyperglycaemia slows gastric emptying in type 1 (insulin-dependent) diabetes mellitus. Diabetologia, 33: 675-680. DOI: 10.1007/BF00400569

15. Rerup, C.C., 1970. Drugs producing diabetes through damage of insulin secreting cells. Pharmacol. Rev., 22: 485-518. http://pharmrev.aspetjournals.org/content/vol22/issue4/

16. Vessal, M., M. Hemmati and M. Vasei, 2003. Antidiabetic effects of quercetin in streptozotocininduced diabetic rats. Comp. Biochem. Physiol. C. Toxicol. Pharmacol., 135C: 357-364. DOI: 10.1016/S1532-0456(03)00140-6

17. Nuraliev, Iu.N. and G.A. Avezov, 1992. The efficacy of quercetin in alloxan diabetes. Eksp. Klin. Farmakol., 55: 42-44. http://www.ncbi.nlm.nih.gov/sites/entrez

18. Xie, W., D. Xing, Y. Zhao, H. Su, Z. Meng, Y. Chen and L. Du, 2005. A new tactic to treat postprandial hyperlipidemia in diabetic rats with gastroparesis by improving gastrointestinal transit. Eur. J. Pharmacol., 510: 113-120. DOI: 10.1016/J.EJPHAR.2005.01.019
19. Umathe, S.N., N.I. Kochar, N.S. Jain and P.V. Dixit, 2009. Gastrointestinal dysfunction in diabetic rats relates with a decline in tissue 1-arginine content and consequent low levels of nitric oxide. Nitric Oxide, 20: 129-133. DOI: 10.1016/j.niox.2008.10.007

20. Fluttert, M., S. Dalm and M.S. Oitzl, 2000. A refined method for sequential blood sample by tail incision. Lab. Anim., 34: 372-378. DOI: 10.1258/002367700780387714.

21. Gillies, P.S. and C.J. Dunn, 2000. Pioglitazone. Drugs, 60: 333-343. http://direct.bl.uk/bld/PlaceOrder.do?UIN=083253 770\&ETOC $=$ RN\&from $=$ searchengine

22. Belcher, G. And D.R. Matthews, 2000. Safety and tolerability of pioglitazone. Exp. Clin. Endocrinol. Diab., 108: S267-S273. DOI: 10.1055/s-2000-8529

23. Seufert, J. and R. Urquhart, 2008. 2-Year effects of pioglitazone add-on to sulphonylurea or metformin on oral glucose tolerance in patients with type 2 diabetes. Diab. Res. Clin. Pract., 79: 453-460. DOI: 10.1016/J.DIABRES.2007.11.014

24. Fujita, Y., Y. Yamada, M. Kusama, T. Yamauchi, J. Kamon, T Kadowaki and T. Iga, 2003. Sex differences in the pharmacokinetics of pioglitazone in rats. Comp. Biochem. Physiol. C Toxicol. Pharmacol., 136: 85-94. DOI: 10.1016/s15320456(03)00194-7

25. Machha, A., F.I. Achike, A.M. Mustafa and M.R. Mustafa, 2007. Quercetin, a flavonoid antioxidant, modulates endothelium-derived nitric oxide bioavailability in diabetic rat aortas. Nitric Oxide, 16 : 442-447. DOI: 10.1016/j.niox.2007.04.001.

26. Friedenberg, F.K. and H.P. Parkman, 2006. Delayed gastric emptying: whom to test, how to test and what to do. Curr. Treat. Options Gastoenterol., $\quad$ 9: 295-304. http://www.ncbi.nlm.nih.gov/pubmed/16836948

27. Shakil, A., R.J. Church and S.S. Rao, 2008. Gastrointestinal complications of diabetes. Am. Fam. Phys., 77: 1697-1702. http://www.ncbi.nlm.nih.gov/pubmed/18619079 